\title{
BMJ Open Costs and quality of life associated with acute upper gastrointestinal bleeding in the UK: cohort analysis of patients in a cluster randomised trial
}

\author{
H E Campbell, ${ }^{1}$ E A Stokes, ${ }^{1}$ D Bargo, ${ }^{1}$ R F Logan, ${ }^{2}$ A Mora, ${ }^{3}$ R Hodge, ${ }^{3}$ A Gray, ${ }^{4}$ \\ M W James, ${ }^{2}$ A J Stanley, ${ }^{5}$ S M Everett, ${ }^{6}$ A A Bailey, ${ }^{7}$ H Dallal, ${ }^{8} \mathrm{~J}$ Greenaway, ${ }^{8}$ \\ C Dyer, ${ }^{9}$ C Llewelyn, ${ }^{3}$ T S Walsh, ${ }^{10}$ S P L Travis, ${ }^{7}$ M F Murphy, ${ }^{9,11}$ V Jairath, ${ }^{7,9}$ \\ on behalf of TRIGGER investigators
}

To cite: Campbell HE, Stokes EA, Bargo D, et al. Costs and quality of life associated with acute upper gastrointestinal bleeding in the UK: cohort analysis of patients in a cluster randomised trial. BMJ Open 2015;5:e007230. doi:10.1136/bmjopen-2014007230

\section{- Prepublication history} and additional material is available. To view please visit the journal (http://dx.doi.org/ 10.1136/bmjopen-2014007230).

Received 19 November 2014 Revised 9 February 2015 Accepted 27 February 2015

CrossMark

For numbered affiliations see end of article.

Correspondence to

EA Stokes;

elizabeth.stokes@dph.ox.ac.uk

\section{ABSTRACT}

Objectives: Data on costs associated with acute upper gastrointestinal bleeding (AUGIB) are scarce. We provide estimates of UK healthcare costs, indirect costs and health-related quality of life (HRQoL) for patients presenting to hospital with AUGIB.

Setting: Six UK university hospitals with $>20$ AUGIB admissions per month, $>400$ adult beds, $24 \mathrm{~h}$ endoscopy, and on-site access to intensive care and surgery.

Participants: 936 patients aged $\geq 18$ years, admitted with AUGIB, and enrolled between August 2012 and March 2013 in the TRIGGER trial of AUGIB comparing restrictive versus liberal red blood cell (RBC) transfusion thresholds.

Primary and secondary outcome measures: Healthcare resource use during hospitalisation and postdischarge up to 28 days, unpaid informal care, time away from paid employment and HRQoL using the EuroQol EQ-5D at 28 days were measured prospectively. National unit costs were used to value resource use. Initial in-hospital treatment costs were upscaled to a UK level.

Results: Mean initial in-hospital costs were $£ 2458$ (SE=£216) per patient. Inpatient bed days, endoscopy and RBC transfusions were key cost drivers.

Postdischarge healthcare costs were £391 (£44) per patient. One-third of patients received unpaid informal care and the quarter in paid employment required time away from work. Mean HRQoL for survivors was 0.74 . Annual initial inhospital treatment cost for all AUGIB cases in the UK was estimated to be $£ 155.5$ million, with exploratory analyses of the incremental costs of treating hospitalised patients developing AUGIB generating figures of between $£ 143$ million and £168 million.

Conclusions: AUGIB is a large burden for UK hospitals with inpatient stay, endoscopy and RBC transfusions as the main cost drivers. It is anticipated that this work will enable quantification of the impact of cost reduction strategies in AUGIB and will inform economic analyses of novel or existing interventions for AUGIB.

\section{Strengths and limitations of this study}

- Acute upper gastrointestinal bleeding (AUGIB) is a common medical emergency often requiring intensive investigation and treatment, yet little is known about associated healthcare costs. This paper reports the largest prospective micro-costing study to date of patients presenting to hospital with a first AUGIB, and provides estimates of patient-level healthcare costs and health-related quality of life $(\mathrm{HRQ} \mathrm{OL})$. Additionally, the indirect cost impact of AUGIB beyond the healthcare sector is explored for the first time.

- The average cost of initial in-hospital treatment is estimated to be £2458 (SE £216) per patient. Applying these cost estimates to national incidence figures for all AUGIB cases (those presenting to hospital $(84 \%)$ and those already in hospital $(16 \%)$ ) suggests the annual cost of initial in-hospital treatment in the UK could be $£ 155.5$ million. Uncertainty around the treatment costs for already hospitalised patients developing AUGIB is explored using sensitivity analysis.

- By day 28 post-AUGIB, one-third of patients had received an average of 9 days of unpaid care and one-quarter who were in paid employment had lost an average of 11.6 working days. These findings should be interpreted with caution as data were missing for over $40 \%$ of the surviving study patients who appeared to have fewer comorbidities than patients who responded to the questions. HRQoL was impaired at day 28 post-AUGIB discharge.

- It is anticipated that by providing information on the key cost drivers associated with AUGIB, this work will enable healthcare providers to identify avenues for cost reduction in AUGIB as well as provide a point of reference for cost-effectiveness research.

Trial registration number: ISRCTN85757829 and NCT02105532. 


\section{INTRODUCTION}

Acute upper gastrointestinal bleeding (AUGIB) is a common medical emergency, and a major cause of morbidity and mortality in western populations. Its incidence is estimated to be between 100 and 200 cases per 100000 resulting in over 50000 admissions annually to UK hospitals. ${ }^{1}$ During hospitalisation, AUGIB frequently results in intensive medical investigation and treatments including laboratory tests, transfusion, and diagnostic and therapeutic strategies to identify and control bleeding such as endoscopy, radiological embolisation and sometimes surgery. Thus, it is likely to impose a substantial burden on healthcare resources although, to date, this has been poorly characterised as outlined in a systematic review. $^{2}$ Additionally, little is known about the indirect cost impact of AUGIB beyond the healthcare sector or health-related quality of life (HRQoL) experienced by patients following the event.

This paper reports the largest prospective microcosting study of patients with AUGIB to date. For the first time, costs both within and beyond the health and social care sector are considered, along with data on patient HRQoL. As part of a randomised trial of red blood cell (RBC) transfusion strategies for AUGIB, we conducted a nested, prospective evaluation of health and social care resource use and costs, unpaid informal care provided to patients by relatives and/or friends, time away from paid employment (productivity losses), and patient HRQoL with the following objectives:

1. To generate an inventory and costing of in-hospital resources utilised by patients presenting to hospital with AUGIB;

2. To explore the range of costs (healthcare, social care, informal care and employers) incurred postdischarge up to 28 days; and

3. To determine levels of HRQoL at day 28 and determinants of these levels.

\section{METHODS}

TRIGGER (transfusion in gastrointestinal bleeding; ISRCTN 85757829 and ClinicalTrials.gov NCT02105532) was a multicentre, pragmatic, cluster randomised trial of restrictive versus liberal RBC transfusion strategies for AUGIB. The trial protocol has previously been published. ${ }^{3}{ }^{4}$ In brief, the aim of the trial was to evaluate the feasibility and safety of implementing a restrictive versus liberal RBC transfusion policy for adult patients admitted to hospital with AUGIB. Six hospitals in the UK took part (in Edinburgh, Glasgow, Leeds, Middlesbrough, Nottingham and Oxford) and recruited 936 patients between August 2012 and March 2013. ${ }^{5}$ Three hospitals were randomised to the liberal transfusion policy $(n=533$ patients) and three to the restrictive policy $(n=403$ patients). The time horizon for the trial was 28 days and the transfusion policy at each institution was maintained for the duration of a patient's index hospital admission up to a maximum of 28 days. As TRIGGER was a feasibility trial intended to inform the design of a subsequent definitive trial incorporating a full costeffectiveness analysis, a formal comparison of resource use and costs between trial arms was not planned.

\section{In-hospital resource use data collection and costs}

Case record forms were designed to capture in-hospital resource use during the index admission for each trial patient and were completed by research staff at each hospital site using patient case notes, drug charts and electronic hospital records. Resource use data recorded included all laboratory tests, medications, intravenous fluids in the first $24 \mathrm{~h}$ and all blood component transfusions. Data were also collected on the number of endoscopies performed (diagnostic and therapeutic), use of surgery or radiological intervention to control bleeding and all adverse events. Full definitions of all trial end points are provided in the protocol. ${ }^{3}{ }^{4}$ To map each patient's journey between clinical areas in the hospital, research staff also recorded admission and discharge dates and times for relevant clinical areas including the emergency department (ED), medical admissions unit, the intensive treatment unit, high dependency unit, endoscopy suite and general medical/surgical wards.

Unit costs (UK £2012/13) for each in-hospital resource use component were obtained from several national sources including the National Health Service (NHS) Reference Costs, NHS Blood and Transplant Price List, NHS Electronic Market Information Tool and the Personal and Social Services Research Unit (PSSRU) ${ }^{6-9}$ Unit costs used and their sources are shown in online supplementary appendix table A1. For each patient, the amount of each type of resource consumed or event occurring was multiplied by its associated unit cost to estimate the total cost of that resource or event.

Blood products were costed to include the cost to the hospital transfusion laboratory of issuing each component. Nursing time associated with administering components was already included in the bed day unit costs used to cost inpatient length of stay and so was not costed separately. NHS Reference Costs provided a unit cost for each type of endoscopy performed and the common adverse events reported, but already included the cost of the hospital stay. Bed days were costed separately in this study and so the proportion of each unit cost that was attributable to bed days was estimated and removed in order to avoid double counting. Details of how all individual resource use items were costed are provided in the online web appendix.

\section{Postdischarge resource use and costs}

At day 28, patients who were discharged from hospital and still alive were interviewed by telephone about health and social care contacts since discharge. Contacts included readmissions to hospital (acute and community hospitals), admissions to nursing homes/residential care, contacts with the hospital ED, outpatient clinics, day hospitals, general practitioners (GPs), nurses and 
any other health or social care provider. The full range of unit costs used to value these contacts is shown in online supplementary appendix table A1. Patients were also asked whether they had received unpaid informal care from family and/or friends since leaving hospital. Shadow pricing was used to cost this time by multiplying the number of hours of care provided by an informal care cost per hour which was estimated by dividing gross national average weekly wage rates (averaged across males and females-see online supplementary appendix table A1) by national average weekly working hours. ${ }^{10}$ This approach assumes that the value of the time given up by individuals to provide unpaid informal care (or the opportunity cost of this time) is adequately reflected by the working wage.

In addition, information was sought on employment status and hours worked prior to the index hospital admission, whether patients had subsequently returned to work, and if so, how many hours they were currently working. For each patient who had not been able to return to work, weekly working hours lost during the 28-day trial period were calculated. This time was costed using gross national average weekly wage rates. For patients returning to work (including at reduced hours), working hours lost were also calculated and costed.

\section{Health-related quality of life}

At day 28 patients completed the three-level EuroQol EQ-5D questionnaire which measures generic HRQoL and contains questions on five dimensions: mobility, selfcare, usual activities, pain and discomfort, and anxiety and depression. ${ }^{11}$ Responses to the EQ-5D were converted into a single index score on a scale where 0 represents dead and 1 represents full health using a tariff estimated by using data from the UK general population. $^{12} 13$

\section{Statistical analysis}

The proportion of patients with missing data was reported for each resource use variable and for the EuroQol EQ-5D questionnaire. Missing data were assumed to be missing at random and multiple imputation (MI) with chained regression equations was used to impute missing health and social care resource use values and EQ-5D HRQoL scores. ${ }^{14}$ Individual regressions were specified for each variable with missing data and five values were imputed for each missing data cell. Rubin's Rule was used when summarising data across the five data sets created using MI. ${ }^{15}$

Owing to the cluster randomisation, multilevel linear regression modelling was used to adjust health and social care resource use, costs and HRQoL estimates for variability between centres (specifically, a random intercept for centre was used). ${ }^{16} 17$ Rather than averaging across all patients as though they were drawn from a single population, multilevel modelling acknowledges the hierarchical nature of the data, that is, that patients are recruited from different centres and have the potential to be more similar to other patients from the same centre than to those between centres. Continuous resource use variables and costs were expressed as means, and SEs and categorical variables as percentages.

\section{National costs}

Using UK population figures and reported data on the incidence of AUGIB, an estimate was made of the annual total number of cases of AUGIB in the UK by age bands. ${ }^{18}{ }^{19}$ Multiplying these figures by the (agespecific) mean estimates of initial in-hospital costs per patient estimated by this study allowed calculations to be made of the potential initial hospital treatment costs of AUGIB in the UK. It is acknowledged that around 16\% of national AUGIB cases will likely manifest in patients already in hospital for another condition, but that the incremental cost of treating a bleed in these patients is unclear (the TRIGGER trial included only new presentations to hospital).$^{20}$ While the analysis above assumes no difference in treatment costs for patients presenting to hospital and patients already resident in hospital, a series of alternative scenarios were explored whereby the mean per patient cost estimates were assumed to be $50 \%$ higher; this was $50 \%$ lower for the estimated $16 \%$ of total cases already in hospital. All analyses were performed using STATA V.12 (StataCorp, College Station, Texas, USA).

\section{RESULTS}

Baseline demographics data are shown in table 1 . The mean (SD) age of patients was 59.4 (20.1) years and $60.5 \%$ were male. Mean Rockall and Blatchford Scores were 2.3 (1.9) and 6.0 (4.6), respectively. In just over a fifth of patients bleeding was attributed to peptic ulcer, in a quarter to oesophagitis/gastritis/duodenitis, and in $12 \%$ to varices. Thirty-two $(3.4 \%)$ patients died during the index hospital admission and $42(4.5 \%)$ patients had died by day 28 .

\section{In-hospital resource use and costs}

Data completeness for in-hospital resource use was 98.6\%. On average patients were transfused 1.58 (SE 0.20) units of RBCs (table 2). One-quarter of patients received therapeutic endoscopy. Only a small proportion of patients underwent surgical $(1.3 \%)$ or radiological $(1.3 \%)$ interventions to control bleeding. Serious adverse events were infrequent (ranging from $0 \%$ for deep vein thrombosis to $1.8 \%$ for acute kidney injury). Mean overall length of hospital inpatient stay was 5.34 (0.29) days. Mean (SE) total in-hospital costs across all trial patients were estimated to be $£ 2458$ (£216), with almost $60 \%$ of this cost attributable to inpatient bed days (£1439 (£111)), 26\% to diagnostic and therapeutic endoscopies (£642 (£71)) and 8\% to RBC transfusion (£198 (£25)) (table 2).

The total annual initial in-hospital treatment costs for AUGIB in the UK were estimated at $£ 155437055$ 
Table 1 Patient demographics and mortality for whole cohort and for patients providing and not providing data at 28 days

\begin{tabular}{|c|c|c|c|c|}
\hline \multirow[b]{2}{*}{ Characteristics and mortality } & \multirow[b]{2}{*}{$\begin{array}{l}\text { Whole } \\
\text { cohort } \\
\mathrm{n}=936\end{array}$} & \multicolumn{3}{|c|}{$\begin{array}{l}\text { Patients not recorded as having died at } 28 \text { days } \\
n=894\end{array}$} \\
\hline & & $\begin{array}{l}\text { Data provided on } \\
\text { health and social care } \\
\text { contacts at } 28 \text { days } \\
n=628\end{array}$ & $\begin{array}{l}\text { No data provided on } \\
\text { health and social care } \\
\text { contacts at } 28 \text { days } \\
n=266\end{array}$ & p Value* \\
\hline Male-n (\%) & $566(60.5)$ & 372 (59.2) & $170(63.9)$ & 0.191 \\
\hline Age (years)-mean (SD) & $59.4(20.1)$ & $60.5(19.4)$ & $54.0(20.8)$ & $<0.01$ \\
\hline Rockall Score-mean (SD) & $2.3(1.9) \dagger$ & $2.3(1.9)$ & $2.1(1.9) \dagger$ & 0.162 \\
\hline Blatchford Score-mean (SD) & $6.0(4.6) \ddagger$ & $6.1(4.6) \S$ & $5.2(4.4) \emptyset$ & $<0.01$ \\
\hline Shock at presentation-n (\%) & $221(23.7)$ ๆ & $133(21.2)^{\star \star}$ & $78(29.3) \dagger$ & 0.031 \\
\hline $\begin{array}{l}\text { Haemoglobin }(\mathrm{g} / \mathrm{dL}) \text { at first measurement- } \\
\text { mean }(\mathrm{SD})\end{array}$ & $11.6(3.3)$ & $11.5(3.3)$ & $12.3(3.2)$ & $<0.01$ \\
\hline \multicolumn{5}{|l|}{ Pre-existing comorbidities—n (\%) } \\
\hline Ischaemic heart disease & $137(14.6)$ & $94(15.0)$ & $33(12.4)$ & 0.316 \\
\hline Cardiac failure & $39(4.2) \dagger$ & $26(4.1) \dagger$ & $7(2.6)$ & 0.446 \\
\hline Hypertension & $232(24.8) \dagger$ & $162(25.8) \dagger$ & $47(17.7)$ & 0.025 \\
\hline Respiratory disease & $158(16.9) \dagger$ & $112(17.8) \dagger$ & 37 (13.9) & 0.283 \\
\hline Renal disease & $54(5.8)$ & $45(7.2)$ & $8(3.0)$ & 0.016 \\
\hline Liver disease & $136(14.5)$ & $93(14.8)$ & $30(11.3)$ & 0.161 \\
\hline Cancer/malignancy & $99(10.6) \dagger$ & $61(9.7) \dagger$ & $25(9.4)$ & 0.800 \\
\hline \multicolumn{5}{|l|}{ Source of bleeding- $\mathrm{n}(\%) \dagger \dagger$} \\
\hline Peptic ulcer & $153(22.7)$ & $97(21.0)$ & $50(27.5)$ & 0.080 \\
\hline Gastro-oesophageal varix & $81(12.0)$ & $56(12.1)$ & $18(9.9)$ & 0.419 \\
\hline Oesophagitis/gastritis/duodenitis & $171(25.4)$ & $116(25.2)$ & 49 (26.9) & 0.645 \\
\hline Mallory-Weiss tear & $30(4.5)$ & $21(4.6)$ & $95(4.9)$ & 0.833 \\
\hline Malignancy & $22(3.3)$ & $13(2.8)$ & $7(3.8)$ & 0.500 \\
\hline Non-identified & 109 (16.2) & $81(17.6)$ & 25 (13.7) & 0.238 \\
\hline Other & $107(15.9)$ & 77 (16.7) & 24 (13.2) & 0.270 \\
\hline \multicolumn{5}{|l|}{ All-cause mortality-n (\%) } \\
\hline In-hospital & $32(3.4)$ & - & - & - \\
\hline 28-day & $42(4.5)$ & - & - & - \\
\hline \multicolumn{5}{|c|}{$\begin{array}{l}{ }^{*} \text { Based on } \chi^{2} \text { for categorical variables and } t \text { test for continuous variables. } \\
\text { †Missing for one patient. } \\
\text { †Missing for seven patients. } \\
\text { §Missing for four patients. } \\
\text { qMissing for three patients. } \\
\star^{\star} \text { Missing for two patients. } \\
\text { ††Not recorded for } 263 \text { patients. }\end{array}$} \\
\hline
\end{tabular}

(table 3). Costs increased with age, ranging from a mean cost of $£ 1143$ for patients aged less than 29 years to $£ 3190$ for patients over 75 years. Assuming that inpatient treatment costs for the $16 \%$ of all patients with AUGIB likely to experience a bleed while already in hospital for another condition were $50 \%$ higher and $50 \%$ lower than the costs observed here generated national cost estimates of $£ 168$ million and $£ 143$ million, respectively.

\section{Postdischarge health and social services resource use and costs}

For postdischarge resource use and costs up to 28 days, $33 \%$ of data were missing. Two hundred and sixty-six $(30 \%)$ of the 894 patients, not recorded as having died by 28 days, were missing data on all postdischarge health and social care contacts. Non-responding patients were significantly younger than responders, were more likely to have presented with shock but were less likely to have had comorbidities, and had lower Blatchford Scores and higher presenting haemoglobin levels (see columns 3 and 4 of table 1).

The mean (SE) number of acute hospital readmission bed days was $0.52(0.08)$ per patient (table 2). The mean (SE) number of outpatient clinic visits was 0.41 (0.06) and the mean number of GP visits was 0.65 (0.06). In total, postdischarge health and social care costs up to 28 days averaged £391 (£44) per patient. Acute hospital readmissions accounted for $36 \%$ of this total cost $(£ 139(£ 21))$; day hospital, clinic and ED visits for $28 \%(£ 109(£ 16))$; and primary/social care contacts for $24 \%$ (£93 (£23)).

Total health and social care costs (in-hospital and postdischarge to 28 days)

Mean (SE) total health and social care costs from hospital presentation up to 28 days were £2851 (£225) per patient (table 2). 
Table 2 Total and mean per patient healthcare resource use and cost (UK £2012/13) for the cohort

\begin{tabular}{|c|c|c|c|}
\hline & $\begin{array}{l}\text { Resource use } \\
\text { Total resource } \\
\text { consumption } \\
\text { across cohort } \\
\mathrm{n}=936\end{array}$ & $\begin{array}{l}\text { Resource use } \\
\text { Mean (SE) per patient or } \\
\text { per cent of cohort } \\
\text { with procedure/event } \\
n=936\end{array}$ & $\begin{array}{l}\text { Cost } \\
\text { Mean (SE) per patient } \\
\text { across whole cohort } \\
n=936\end{array}$ \\
\hline \multicolumn{4}{|l|}{ In-hospital episode } \\
\hline \multicolumn{4}{|l|}{ Blood products $\dagger$} \\
\hline RBC units & 1478 & $1.58(0.20)$ & $£ 198.13(£ 24.55)$ \\
\hline FFP units & 174 & $0.19(0.05)$ & $£ 5.72(£ 1.35)$ \\
\hline Platelets units & 61 & $0.07(0.02)$ & $£ 13.84(£ 3.97)$ \\
\hline Cryoprecipitate units & 12 & $0.01(0.01)$ & $£ 2.45(£ 1.53)$ \\
\hline Single factor VIla dose & 2 & $0.25 \%$ & $£ 2.55(£ 46.86)$ \\
\hline \multicolumn{4}{|l|}{ Laboratory testing $\ddagger$} \\
\hline FBC tests & 4592 & $4.88(0.26)$ & $£ 16.47(£ 0.87)$ \\
\hline Urea and electrolytes tests & 4266 & $4.52(0.31)$ & $£ 5.74(£ 0.39)$ \\
\hline Liver function tests & 3081 & $3.29(0.44)$ & $£ 2.27(£ 0.30)$ \\
\hline Coagulation tests & 2406 & $2.55(0.30)$ & $£ 17.22(£ 2.06)$ \\
\hline \multicolumn{4}{|l|}{ Medications§ } \\
\hline Medications & Variousף & Various & $£ 23.76(£ 5.59)$ \\
\hline \multicolumn{4}{|l|}{ Fluids in $24 \mathrm{~h}^{\star \star}$} \\
\hline Colloids (L) & 117 & $0.12(0.04)$ & $£ 0.63(£ 0.23)$ \\
\hline Crystalloids (L) & 1606 & $1.72(0.07)$ & $£ 2.44(£ 0.10)$ \\
\hline \multicolumn{4}{|l|}{ Endoscopiest† } \\
\hline Diagnostic & 506 & $0.57(0.06)$ & $£ 371.13(£ 36.24)$ \\
\hline Therapeutic & 277 & $0.29(0.05)$ & $£ 270.40(£ 44.83)$ \\
\hline \multicolumn{4}{|l|}{ 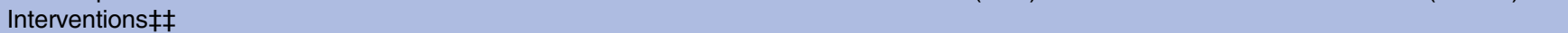 } \\
\hline Surgical & 12 & $1.3 \%$ & $£ 19.37(£ 5.56)$ \\
\hline Radiological & 12 & $1.3 \%$ & $£ 33.42(£ 16.14)$ \\
\hline \multicolumn{4}{|l|}{ Adverse events in hospitalł‡ } \\
\hline Acute coronary syndrome & 4 & $0.4 \%$ & $£ 3.77(£ 1.88)$ \\
\hline Stroke & 3 & $0.3 \%$ & $£ 4.77(£ 2.75)$ \\
\hline Acute kidney injury & 17 & $1.8 \%$ & $£ 27.69(£ 8.79)$ \\
\hline Pulmonary embolism & 5 & $0.5 \%$ & $£ 4.01(£ 1.79)$ \\
\hline Deep vein thrombosis & 0 & $0 \%$ & $£ 0.00(£ 0.00)$ \\
\hline \multicolumn{4}{|l|}{ Length of hospital stay } \\
\hline Total length of hospital stay (days) & 4997 & $5.34(0.29)$ & $£ 1438.97(£ 110.86)$ \\
\hline Total in-hospital costs & & - & $£ 2457.58$ (£215.73) \\
\hline \multicolumn{4}{|l|}{ Postdischarge care $\S \S, \eta \uparrow,{ }^{, \star *}$} \\
\hline Acute hospital readmission bed days & 490 & $0.52(0.08)$ & $£ 138.96(£ 20.75)$ \\
\hline Community hospital admission bed days & 66 & $0.07(0.04)$ & $£ 18.80(£ 10.62)$ \\
\hline Nursing/residential care admission bed days & 367 & $0.38(0.20)$ & $£ 32.05(£ 17.12)$ \\
\hline Number of ED visits & 160 & $0.17(0.03)$ & $£ 17.33(£ 2.56)$ \\
\hline Number of hospital clinic visits & 374 & $0.41(0.06)$ & $£ 50.42(£ 6.93)$ \\
\hline Number of day hospital visits & 87 & $0.10(0.03)$ & $£ 41.22(£ 11.37)$ \\
\hline Number of visits to GP & 608 & $0.65(0.06)$ & $£ 29.44(£ 2.72)$ \\
\hline Number of GP home visits & 98 & $0.10(0.02)$ & $£ 11.88(£ 2.01)$ \\
\hline Number of visits to practice nurse & 183 & $0.20(0.03)$ & $£ 2.67(£ 0.42)$ \\
\hline Number of home visits from district nurse & 313 & $0.34(0.09)$ & $£ 13.44(£ 3.42)$ \\
\hline Number of other health/social visits & 700 & $0.77(0.48)$ & $£ 35.00(£ 21.99)$ \\
\hline Total postdischarge costs to 28 days & - & - & $£ 391.20(£ 43.55)$ \\
\hline Total costs to 28 days & - & - & $£ 2850.85(£ 225.15)$ \\
\hline \multicolumn{4}{|c|}{ 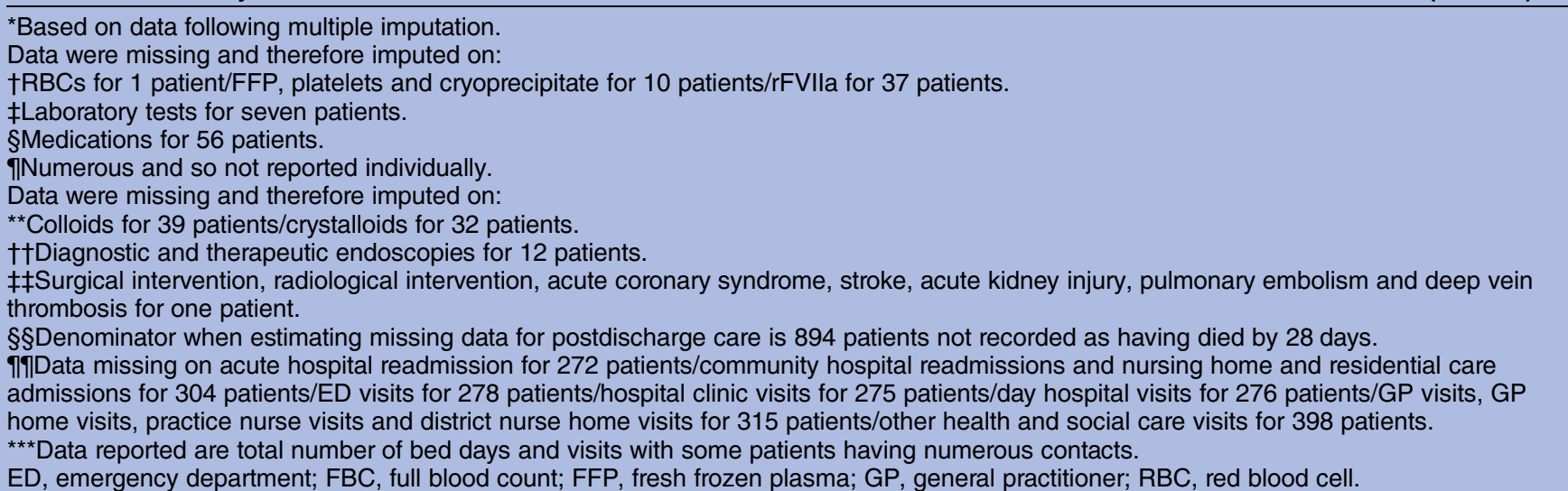 } \\
\hline
\end{tabular}


Table 3 Estimate of annual initial hospital costs for acute upper gastrointestinal bleeding (AUGIB) in the UK

\begin{tabular}{|c|c|c|c|c|c|}
\hline $\begin{array}{l}\text { Age bands } \\
\text { (years) }\end{array}$ & UK Population* & $\begin{array}{l}\text { AUGIB incidence } \\
\text { per } 100 \text { 000/yeart }\end{array}$ & $\begin{array}{l}\text { Annual number of } \\
\text { patients with AUGIB } \\
\text { in UK population }\end{array}$ & $\begin{array}{l}\text { Mean total initial } \\
\text { hospital cost } \\
\text { estimates } \ddagger\end{array}$ & $\begin{array}{l}\text { Annual } \\
\text { total costs }\end{array}$ \\
\hline $16-29$ & 11806800 & 23 & 2716 & $£ 1143(n=91)$ & $£ 3104535$ \\
\hline 30-44 & 12843400 & 41 & 5266 & $£ 2053(n=150)$ & $£ 10811709$ \\
\hline $45-59$ & 12605800 & 69 & 8698 & $£ 2183(n=224)$ & $£ 18990830$ \\
\hline $60-64$ & 3624400 & 109 & 3951 & $£ 2686(n=78)$ & $£ 10613733$ \\
\hline $65-74$ & 5820900 & 214 & 12457 & $£ 2749(n=142)$ & $£ 34248977$ \\
\hline $75+$ & 5020000 & 485 & 24347 & $£ 3190(n=251)$ & $£ 77667271$ \\
\hline Total & 51721300 & - & 57434 & - & $£ 155437055$ \\
\hline
\end{tabular}

${ }^{*}$ Data on population from Office for National Statistics $2012 .{ }^{19}$

†AUGIB incidence figures taken from Rockall et al. ${ }^{18}$

¥Mean cost estimates based on analysis of TRIGGER data reported in this paper.

Non-health and social care costs-unpaid informal care and productivity losses

At day 28, of the 894 patients not recorded as having died, $523(59 \%)$ provided information on unpaid informal care and $526(59 \%)$ on time away from paid employment.

Approximately one-third $(180 / 523,34 \%)$ of patients reported having received unpaid informal care from a relative or friend after leaving hospital. Table 4 shows that over the trial period, these patients received a mean (SE) of 69 (10) hours of unpaid care which is equivalent to around $9(7.5 \mathrm{~h})$ working days. Cost estimates for this time were averaged across all patients completing the questions $(n=523)$ which produced a mean (SE) cost of $£ 357$ ( $£ 88)$.

Approximately 23\% (123/526) of patients reported that they had been in paid employment prior to presenting to hospital with AUGIB. Table 4 shows 34\% (41/121) of these patients reported that they had not been able to return to work; mean working hours lost in this group were estimated to be 125 (or around 17 working days) per patient. Of the $66 \%(80 / 121)$ patients who were able to return to work, a mean of 66 working hours (9 working days) were lost due to absence and reduced working hours. Average working time lost across all patients who had been in paid employment was 11.6 days. Costing time away from the workplace (absence and reduced hours) and averaging across all patients completing the questions $(n=526)$ estimated productivity losses to be $£ 275$ (£27) per patient.

\section{Health-related quality of life}

EQ-5D data were missing for 390/936 (42\%) patients as telephone contact at day 28 could not be made. Of the surviving patients with data, over $40 \%$ reported

Table 4 Reported data on unpaid informal care and productivity costs at 28 days

\begin{tabular}{|c|c|c|}
\hline & $\begin{array}{l}\text { n (\%) Missing data } \\
n=894^{\star}\end{array}$ & Reported data \\
\hline Unpaid informal care & $371(41.5 \%)$ & $\mathrm{n}=523$ \\
\hline Receiving any unpaid informal care-n (\%) & & $\begin{array}{l}180 / 523(34.4 \%) \\
n=180\end{array}$ \\
\hline Hours of unpaid informal care if received-mean (SE) & & $\begin{array}{l}69.17(10.3) \dagger \\
\mathrm{n}=523\end{array}$ \\
\hline Total cost of unpaid informal care & & $£ 357.30(£ 88.16) \ddagger$ \\
\hline Employment status & $368(41.2 \%)$ & $\mathrm{n}=526$ \\
\hline In paid employment before admission-n (\%) & & $123 / 526(23.4 \%)$ \\
\hline Not returned to work since admission-n (\%) & & $\begin{array}{l}41 / 121(33.9 \%) \S \\
n=41\end{array}$ \\
\hline Hours of work lost if not returned-mean (SE) & & $125.21(7.8) \rrbracket$ \\
\hline Returned to work since admission-n (\%) & & $\begin{array}{l}80 / 121(66.1 \%) \S \\
n=80\end{array}$ \\
\hline Hours of work lost if returned to work-mean (SE) & & $66.30(5.5)^{\star \star}$ \\
\hline Total cost of lost working hours-mean (SE) & & $£ 274.58(£ 26.50) \dagger \dagger$ \\
\hline \multicolumn{3}{|c|}{$\begin{array}{l}\text { Italics typeface are used for average hours within each section. } \\
{ }^{*} n=894 \text { patients not recorded as having died at } 28 \text { days. } \\
\text { †Mean imputation used for hours of informal care missing for } 32 / 180 \text { patients. } \\
\text { fCosts of informal care adjusted for clustering and averaged across all } 523 \text { patients. } \\
\S \text { Return to work field missing for } 2 / 123 \text { patients. } \\
\text { १Mean imputation used for hours of lost work time data missing for } 1 / 41 \text { patients who were known not to have returned to work. } \\
\star_{* *} \text { Mean imputation used for hours lost data missing for } 7 / 80 \text { patients who were known to have returned to work. } \\
\text { ††Productivity costs adjusted for clustering and averaged across all } 526 \text { patients. }\end{array}$} \\
\hline
\end{tabular}




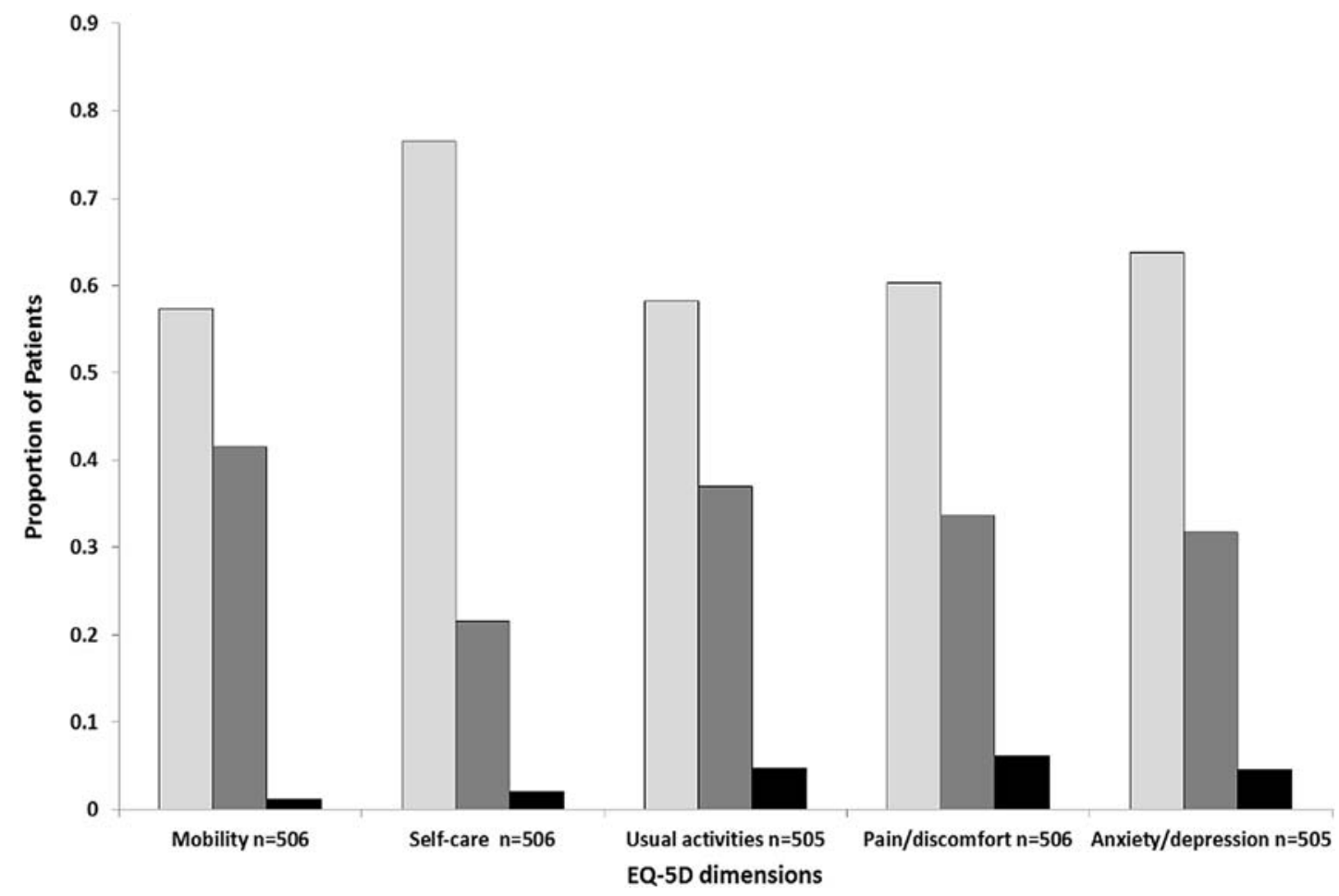

Figure 1 Distribution of patient responses across levels for each of the five EQ-5D domains. $₫$ Level 1-no problems; $₫$ level 2 —some problems; - level 3-extreme problems.

having some problems (level 2) with mobility and over $30 \%$ reported some problems with usual activities, pain and discomfort, and anxiety and depression (figure 1). The mean (SE) EQ-5D HRQoL score at 28 days across the cohort (assigning a zero score to patients who had died) was 0.683 (0.01); MI and adjustment for clustering of this value increased it to $0.701(0.02)$. For surviving patients the mean score was $0.735(0.02)$. By comparison, the mean EQ-5D score for the UK general population has previously been reported to be $0.86 .^{21}$

\section{DISCUSSION}

This study has explored resource use and cost implications for patients presenting to hospital with AUGIB for the NHS and social services up to 28 days postpresentation. Mean in-hospital costs were estimated to be £2458 (SE $£ 216)$ per patient; $60 \%$ of this cost was attributable to inpatient bed days, $26 \%$ to endoscopy and $8 \%$ to RBCs. Local NHS Hospital Trusts may find it useful to compare their own average reimbursement figures for patients with AUGIB to these cost estimates. Costs of health and social care contacts beyond hospital discharge up to 28 days suggested further costs of £391 (SE £44) per patient.

Combining data from this study with UK population figures and estimates of AUGIB incidence, the total annual UK cost of initial hospital treatment was estimated to be $£ 155.5$ million with just over $£ 93$ million $(60 \%)$ of this cost attributable to in-hospital length of stay, £38.5 million (25\%) to endoscopy and £12.6 million $(8 \%)$ to RBCs. This amounts to approximately
$0.13 \%$ of total NHS spending ( $£ 120$ billion in England, Scotland, Wales and Northern Ireland in 2010/2011). ${ }^{22}$ The reliability of these figures rests on a number of study parameters, perhaps most important of which is whether the patients in this study are representative of all patients with AUGIB presenting to hospital. A comparison of study patients with admissions to hospital in the 2007 UK audit of AUGIB (a cross-sectional audit of 208 UK hospitals) suggests similar mean ages (59.4 vs 62.6 years), gender $(60.5 \%$ male vs $60 \%$ male), median presenting haemoglobin (11.9 vs $11.4 \mathrm{~g} / \mathrm{dL})$, median Rockall Score (2 vs 2), aetiology of bleeding and median hospital stay ( 4 vs 5 days). ${ }^{20}$ In-hospital mortality for new presentations in the 2007 audit, however, was double that observed in the TRIGGER trial $(6.8 \%$ vs $3.4 \%)$. This observation may be attributable to a number of reasons: first, TRIGGER excluded patients with exsanguinating bleeding, a group associated with greater mortality; and second, improvements in care, namely, better access to emergency endoscopy than that was present in the nationwide audit in 2007. It must also be acknowledged that the incidence figures for AUGIB in the UK used in this study when estimating national costs include a proportion $(16 \%)$ of patients already hospitalised when developing a bleed. Although the incremental cost of treatment for these patients was not calculated here (the TRIGGER trial included only patients presenting to hospital), analyses assuming costs for this subgroup of patients were $50 \%$ higher and $50 \%$ lower than those observed here, altered the national cost estimates by just $8 \%$. 
Knowledge of key cost drivers in the treatment of AUGIB can enable healthcare providers to identify avenues for cost reduction and be a point of reference for cost-effectiveness research. For example, a large UK study has shown that more timely endoscopy for AUGIB ( $<12$ vs $>12 \mathrm{~h}$ postpresentation) can reduce hospital inpatient stay (shown here to be responsible for $60 \%$ of in-hospital costs for this population) by an average of 1.7 days. ${ }^{23}$ Any cost savings brought about via a reduction in hospital stay would, however, need to be offset against the cost of additional resources required to facilitate more rapid access to endoscopy and to be considered alongside any potential impact on patient outcomes. Similarly, the TRIGGER feasibility trial reported a trend towards improved safety with a restrictive $\mathrm{RBC}$ transfusion policy and observed a reduction in the mean number of RBC units transfused from 1.91 under a liberal policy to 1.21 (mean difference 0.7 units, $95 \%$ CI -1.6 to 0.3$).{ }^{5}$ Using these findings together with the national cost estimates in table 3 and assuming that half of the patients with AUGIB in the UK are already exposed to a restrictive transfusion policy, changing practice for the remaining $50 \%$ of patients could potentially save 20102 units of RBCs, which at a cost of £123.31 per unit amounts to savings of $£ 2.48$ million; however, even this may be an underestimate because the percentage of hospitals currently using a restrictive policy is likely to be less than 50\%. Furthermore, true cost savings will be greater when the input of hospital transfusion laboratories and nursing staff who issue and administer RBCs are accounted for.

To the best of our knowledge, this is the first study to explore the impact of AUGIB on costs beyond the healthcare sector. The observation that just over a third of patients contacted by telephone at day 28 reported that they had received an average of 9 days of unpaid informal care from family members and/or friends is noteworthy, as is the finding that almost a quarter of patients answering questions on employment status reported that they were in paid employment prior to their AUGIB and lost an average of 11.6 days of work as a result of their condition. These data highlight the importance of assessing the impact of new treatments and interventions for AUGIB beyond the healthcare sector.

Previous work in this area is limited. A systematic review identified just seven studies reporting on healthcare resource use and costs in AUGIB. ${ }^{2}$ Differences between these studies and the work presented here in terms of jurisdiction (six of the seven studies identified were from the USA or Canada), methodologies (all studies used retrospective data collection with some using claims reimbursement data and possibly valuing resource use data with charges rather than costs) and relevance to current practice (the most recently published study analysed data up to 2003 only and did not report a breakdown of inpatient resource use) imply that a comparison across studies is unlikely to be informative.
Few data have been reported on HRQoL in patients with AUGIB. In 2007, Leontiadis $e t a l^{24}$ administered the EuroQol EQ-5D questionnaire to 57 patients surviving an upper gastrointestinal bleed in two English hospitals at 7 days postbleed or hospital discharge (whichever was earlier), and at 4 weeks postbleed. A single index score of 0.45 was reported at 7 days/hospital discharge and 0.78 at 4 weeks. This latter score is similar to the value of 0.735 seen for surviving patients in our study at the same time point, although a limitation of our data is the lack of information on baseline HRQoL at presentation. Our larger sample size and the multicentre nature of the study, conducted in geographically diverse units, does enhance the generalisability of our results to broader UK practice.

A number of uncertainties in the data presented should be acknowledged. First, over $30 \%$ of patients had no healthcare resource use follow-up data and over $40 \%$ had no informal care, employment or HRQoL data. Despite study research nurses attempting to contact each patient by telephone, the difficulties encountered with follow-up appear to be due at least in part to a combination of the cohort's demographic and lifestyle factors, or comorbidities. A comparison of responding and nonresponding patients suggested non-responders were younger and in better health than responders, with lower Blatchford Scores and fewer comorbidities. While a number of these variables were included as predictors in the models used to impute missing postdischarge healthcare resource use data, we chose not to impute informal care costs and productivity losses given the magnitude of the missing data issue. Even in spite of the uncertainty surrounding these estimates, we believe inclusion of these data still adds value to the paper for two main reasons. First, our data have shown (perhaps unexpectedly) that despite an average age of almost 60 years, at least a quarter of patients were still in paid employment and lost time away from the workplace as a result of their bleed (this percentage is likely to be even higher if the younger healthier patients with missing data were also in paid employment). In light of these findings it would, therefore, be important for assessments of the costeffectiveness of interventions or policies for AUGIB to seek the impact of both within and beyond the healthcare sector. Second (and again perhaps unexpectedly) this study has shown that it appears to be younger healthier patients who are more difficult to contact posthospital discharge. This observation may assist researchers following this patient group in the future to develop tailored data collection strategies, for example, combined use of telephone contact and postal questionnaires for younger patients who have presumably returned to work and normal social activities.

Second, we costed the most common adverse events, but noted that 90 patients were recorded as having at least one 'other' adverse event during the course of the trial. Events included sepsis, pneumonia, oedema, seizure, advanced pancreatic cancer resulting in death 
and end-stage liver disease, etc. While any change in the duration of the index hospital inpatient stay, medication, laboratory tests and readmissions to hospital arising as a consequence of such events would have been captured by the trial, it was not possible to collect detailed information on all treatments administered for such events, and therefore, costs may be slightly underestimated.

Finally, analyses assumed cost data were normally distributed. While costs may be better analysed using generalised gamma models (to handle skewness), it proved difficult to run such models within the context of this study given the need to deal with simultaneous issues of missing data, clustering and high proportions of patients with zero costs for many individual resource use items. Other researchers have recently noted a lack of statistical methods for dealing with these issues and have called for further methodological studies to consider approaches for use, particularly in trials with high proportions of zero costs. ${ }^{25}$ Studies have shown that methods assuming normality can be quite robust even when costs are highly skewed; however, within this study it is difficult to know whether the precision of cost estimates would have improved had it been possible to estimate an aggregated multilevel generalised gamma model across MI data sets. ${ }^{17}$

\section{CONCLUSIONS}

This is the first study to quantify the healthcare costs associated with AUGIB in the UK. Inpatient stay, endoscopy and RBCs are key cost drivers. Costs of AUGIB beyond the healthcare sector are likely to be considerable and should be considered in assessments of future interventions for AUGIB. These data will assist healthcare agencies in interpreting the cost implications of care processes for AUGIB and will help clinicians and researchers to determine the economic impact of novel and existing interventions for AUGIB.

\footnotetext{
Author affiliations

${ }^{1}$ Nuffield Department of Population Health, Health Economics Research Centre, University of Oxford, Oxford, UK

${ }^{2}$ Nottingham Digestive Diseases NIHR Biomedical Research Unit, University of Nottingham, Nottingham, UK

${ }^{3}$ Clinical Trials Unit, NHS Blood and Transplant, Cambridge, UK

${ }^{4}$ Department of Emergency Medicine, Royal Infirmary of Edinburgh, Edinburgh, UK

${ }^{5}$ Gastrointestinal Unit, Glasgow Royal Infirmary, Glasgow, UK

${ }^{6}$ Department of Gastroenterology, St James's University Hospital, Leeds, UK

${ }^{7}$ Translational Gastroenterology Unit, Nuffield Department of Medicine, University of Oxford, Oxford, UK

${ }^{8}$ Department of Gastroenterology, James Cook University Hospital, Middlesbrough, UK

${ }^{9}$ Clinical Trials Unit, NHS Blood and Transplant, Oxford, UK

${ }^{10}$ Centre for Inflammation Research, Queen's Medical Research Institute, University of Edinburgh, Edinburgh, UK

${ }^{11}$ National Institute for Health Research (NIHR) Oxford Biomedical Research

Centre, Oxford University Hospitals and University of Oxford, Oxford, UK
}

Acknowledgements The trial benefited from the support provided by the NIHR Clinical Research Networks. The authors thank the independent members of the TSC and the DMC, members of the lay focus group and patient panel who inputted into the trial design, and Age UK Abingdon for allowing us to conduct a focus group with members of the public. They thank all clinical teams in participating centres for their support and for following the transfusion policies, and are grateful to the research staff for collecting the study data. Above all, they would like to thank the patients for participating in the study.

Collaborators TRIGGER trial collaboration: Trial Management Group: VJ, MFM, Brennan Kahan, MWJ, AG, TSW, EAS, AJS, CD, AM, RH, CL. Data Monitoring Committee (DMC): Michael Greaves (Chair), Bob Walt, Marc Turner, Keith Wheatley. Trial Steering Committee: Chris Hawkey (Chair), Duncan Wyncoll, Jonathan Benger, TSW, RFL, SPLT, Caroline Doré, HEC, Cliff Gorton (Independent, lay member), Sarah Meredith, CL.

Contributors HEC was involved in the design of the costing aspects of the study, conducted the data analysis, and drafting and revision of the manuscript, and approval of the final version. EAS was involved in the design of the costing aspects of the study, assisted with the data analysis and revision of the manuscript, and approval of the final version. DB assisted with the data analysis and revision of the manuscript, and approval of the final version. RFL and SPLT were involved in the study design, interpretation of data, revision of the manuscript and approval of the final version. AG was involved in the study design, revision of the manuscript and approval of the final version. AM, RH, MWJ, AJS, SME, AAB, HD and JG were involved in the acquisition of data, revision of the manuscript and approval of the final version. CD, CL and TSW were involved in the study design, revision of the manuscript and approval of the final version. MFM was responsible for study conception and design, interpretation of data, revision of the manuscript, and approval of the final version, and was co-chief investigator of the TRIGGER trial. VJ was responsible for study conception and design, interpretation of data, drafting and revision of the manuscript, and approval of the final version, and was co-chief investigator of the TRIGGER trial.

Funding The project was funded by NHS Blood and Transplant Research and Development (grant number 10-09-CSU) and run by NHSBT Clinical Trials Unit (formerly NHSBT/MRC Clinical Studies Unit).

Competing interests None declared.

Ethics approval Approval was obtained for the TRIGGER TRial in England (REC Reference 12/SC/0062) and Scotland (REC Reference 12/SS/0023).

Provenance and peer review Not commissioned; externally peer reviewed.

Data sharing statement No additional data are available.

Open Access This is an Open Access article distributed in accordance with the Creative Commons Attribution Non Commercial (CC BY-NC 4.0) license, which permits others to distribute, remix, adapt, build upon this work noncommercially, and license their derivative works on different terms, provided the original work is properly cited and the use is non-commercial. See: http:// creativecommons.org/licenses/by-nc/4.0/

\section{REFERENCES}

1. Crooks C, Card T, West J. Reductions in 28-day mortality following hospital admission for upper gastrointestinal hemorrhage. Gastroenterology 2011;141:62-70.

2. Parker DR, Luo X, Jalbert J, et al. Impact of upper and lower gastrointestinal blood loss on healthcare utilization and costs: a systematic review. J Med Econ 2011;14:279-87.

3. Kahan BC, Jairath V, Murphy MF, et al. Update on the transfusion in gastrointestinal bleeding (TRIGGER) trial: statistical analysis plan for a cluster-randomised feasibility trial. Trials 2013;14:206.

4. Jairath V, Kahan BC, Gray A, et al. Restrictive vs liberal blood transfusion for acute upper gastrointestinal bleeding: rationale and protocol for a cluster randomized feasibility trial. Transfus Med Rev 2013;27:146-53.

5. Jairath V, Kahan BC, Gray A, et al. Restrictive versus liberal blood transfusion for acute upper gastrointestinal bleeding: pragmatic, cluster randomised feasibility trial. Lancet 2014 . In Press.

6. Department of Health. NHS National Schedule of Reference Costs 2012-13. https://www.gov.uk/government/publications/nhsreference-costs-2012-to-2013 (accessed 12 Jan 2014).

7. NHS Blood and Transplant. Price list 2012/2013. NHS Blood and Transplant, 2012. 
8. Department of Health Commercial Medicines Unit. Electronic Market Information Tool. https://www.gov.uk/government/publications/drugsand-pharmaceutical-electronic-market-information-emit (accessed 12 Jan 2014).

9. Curtis L. Unit costs of health and social care 2013. Canterbury: Personal and Social Services Research Unit University of Kent, 2013.

10. Bovill D. Patterns of pay: estimates from the Annual Survey of Hours and Earnings, UK, 1997 to 2013. http://www.ons.gov.uk/ons/ dcp171766_353368.pdf (accessed 1 May 2014).

11. Brooks R. EuroQol: the current state of play. Health Policy 1996;37:53-72

12. Dolan P, Gudex C, Kind P, et al. A social tariff for EuroQol: results from a UK General Population Survey (Discussion Paper No. 138). York, England: Centre for Health Economics University of York, 1995.

13. Dolan P. Modeling valuations for EuroQol health states. Med Care 1997;35:1095-108.

14. White IR, Royston P, Wood AM. Multiple imputation using chained equations: issues and guidance for practice. Stat Med 2011;30:377-99.

15. Briggs $\mathrm{A}$, Clark $\mathrm{T}$, Wolstenholme $\mathrm{J}$, et al. Missing...presumed at random: cost-analysis of incomplete data. Health Econ 2003;12:377-92.

16. Ng ES-W, Diaz-Ordaz K, Grieve R, et al. Multilevel models for cost-effectiveness analyses that use cluster randomised trial data: an approach to model choice. Stat Methods Med Res 2013 Published Online First.

17. Gomes M, Ng ES-W, Grieve R, et al. Developing appropriate methods for cost-effectiveness analysis of cluster randomized trials. Med Decis Making 2012;32:350-61.
18. Rockall TA, Logan RF, Devlin HB, et al. Incidence of and mortality from acute upper gastrointestinal haemorrhage in the United Kingdom. BMJ 1995;311:222-6.

19. Office for National Statistics. Population estimates for UK, England and Wales, Scotland and Northern Ireland, Mid-2012. http://www. ons.gov.uk/ons/publications/re-reference-tables.html?edition=tcm\% 3A77-319259 (accessed 6 Jun 2014).

20. Hearnshaw SA, Logan RFA, Lowe D, et al. Acute upper gastrointestinal bleeding in the UK: patient characteristics, diagnoses and outcomes in the 2007 UK audit. Gut 2011;60:1327-35.

21. Szende A, Janssen B. Population norms for the EQ-5D. In: Szende A, Janssen B, Cabases J, eds. Self-reported population health: an international perspective based on EQ-5D. New York: Springer, 2014:19-30

22. National Audit Office. Healthcare across the UK: a comparison of the NHS in England, Scotland, Wales and Northern Ireland. London: The Stationary Office, 2012.

23. Jairath V, Kahan BC, Logan RFA, et al. Outcomes following acute nonvariceal upper gastrointestinal bleeding in relation to time to endoscopy: results from a nationwide study. Endoscopy 2012:44:723-30.

24. Leontiadis GI, Sreedharan A, Dorward S, et al. Systematic reviews of the clinical effectiveness and cost-effectiveness of proton pump inhibitors in acute upper gastrointestinal bleeding. Health Technol Assess Rep 2007;11:1-164.

25. Díaz-Ordaz K, Kenward MG, Grieve R. Handling missing values in cost effectiveness analyses that use data from cluster randomized trials. J R Stat Soc A 2014;177:457-74. 